\title{
Mortality from congenital malformations by mother's country of birth
}

\author{
R BALARAJAN ${ }^{2}$ AND M MCDOWALL \\ From the Medical Department, ${ }^{1}$ South West Thames Regional Health Authority, 40 Eastbourne Terrace, \\ London W2 3QR; Department of Clinical Epidemiology, ${ }^{2}$ St George's Hospital Medical School, Blackshaw \\ Road, London SW17; and Medical Statistics Division, ${ }^{3}$ Office of Population Censuses \& Surveys, St \\ Catherine's House, Kingsway, London WC2B $6 \mathrm{JP}$.
}

SUMMARY Mortality from congenital malformations by mother's country of birth was examined in England and Wales between the years 1976 and 1980, based on stillbirths and infant deaths. There were 18870 stillbirths and infant deaths attributed to congenital malformations in this period, of which $2375(13 \%)$ were to mothers born outside the United Kingdom. There were excess deaths from malformations among Pakistani, Indian/Bangladeshi, African, and Irish mothers. In contrast, West Indian mothers had a consistent deficit in deaths from malformations over the study period. The significance of these findings is discussed.

\section{Background}

The aetiology of most congenital malformations is unknown. The incidence of certain malformations is known to be related to factors such as the age of the mother, season of birth, and ethnicity. The variations between the different ethnic groups may be the consequence of environment, genetic predisposition or possible interactions of these two factors.

In England and Wales in 1980, about 13\% of all live births were to mothers born outside the United Kingdom, of which $8.5 \%$ were to those born in the New Commonwealth and Pakistan. We have in this study analysed all stillbirths and infant deaths in England and Wales for the years 1976-80 to explore variations in mortality from congenital malformations according to the mother's country of birth. Our analysis at the national level has been restricted to mortality from congenital malformations as the National Congenital Malformation Monitoring Scheme ${ }^{1}$ does not record information on the country of birth or ethnic origin of the mother.

\section{Material and methods}

All stillbirths and infant deaths in England and Wales with congenital malformations as the underlying cause of death were extracted from the Office of Population Censuses and Surveys linked files ${ }^{2}$ for the years $1976-80$ by mother's country of birth. Age specific malformation mortality rates for England and Wales were computed by mother's age in five year age groups $(15-19,20-24,25-29,30-34,2$ $35-39,40-44,45+)$ using all still and live births in England and Wales as the denominator. These were applied to the corresponding age specific total births by country of birth of the mother to generate expected deaths. The total observed and expected deaths were examined in the form of a standardised mortality ratio (SMR). The analysis was done separately for two calendar periods, $1975-78$ and 1979-80, to check consistency and to allow for any possible variations due to the change in the revisions of the International Classification of Diseases ${ }^{3}$ in 1979. The malformations and their corresponding ICD categories are given in table 1 .

\section{Results}

There were 18870 stillbirths and infant deaths attributed to congenital malformations in England and Wales between 1975 and 1980 . Of these, 16495 $(87.4 \%)$ were to mothers born within the United Kingdom; $1260(6 \cdot 7 \%)$ to mothers from the Indian subcontinent (India, Pakistan, and Bangladesh); $304(1.6 \%)$ to mothers from Africa; $368(2.0 \%)$ to mothers from the Irish Republic; $154(0.8 \%)$ to mothers from the West Indies; and $289(1.5 \%)$ to mothers born elsewhere. The SMRs for all malformations were highest among infants born to mothers from Pakistan-179 (1975-8) and 226 
Table 1 Malformations and ICD categories

\begin{tabular}{|c|c|c|}
\hline \multirow[b]{2}{*}{ Group malformations } & \multicolumn{2}{|l|}{ ICD category } \\
\hline & 8th Revision & 9th Revision \\
\hline Anencephalus & 740 & 740 \\
\hline Spina bifida & 741 & 741 \\
\hline Other central nervous system anomalies & $742-743$ & 742 \\
\hline Circulatory system anomalies & $746-747$ & $745-747$ \\
\hline Respiratory system anomalies & 748 & 748 \\
\hline \multicolumn{3}{|l|}{$\begin{array}{l}\text { Cleft palate and cleft lip, and other } \\
\text { anomalies of upper alimentary tract and }\end{array}$} \\
\hline & 749-751 & $749-751$ \\
\hline \multicolumn{3}{|l|}{ Anomalies of genital organs and urinary } \\
\hline system & $752-753$ & $752-753$ \\
\hline Limb and other musculoskeletal anomalies & $754-756$ & $754-756$ \\
\hline
\end{tabular}

(1979-80)-followed by those from India and Bangladesh, 137 and 136; Africa, 119 and 123; and the Irish Republic, 109 and 117. West Indian mothers had low SMRs of 68 and 60 for the two periods in the study.

CENTRAL NERVOUS SYSTEM MALFORMATIONS There were 9317 deaths attributed to the central nervous system, of which $42 \%$ were due to anencephaly and $37 \%$ to spina bifida. The SMRs, by country of birth of mother, for this group are shown in table 2. SMRs from anencephaly were highest in infants born to Indian/Bangladeshi mothers followed by infants born to Pakistani and Irish mothers. The differences among these groups are less marked for spina bifida, though all of them show excess deaths compared to the home population. Other central nervous system anomalies showed significant excesses in the infants born to Pakistani mothers, with SMRs of 229 and 358, followed by infants born to Indian/Bangladeshi and Irish mothers.
ANOMALIES OF THE CARDIOVASCULAR AND RESPIRATORY SYSTEMS

SMRs, by country of birth of mother, for malformations of the cardiovascular system are shown in table 3 . There were 4574 deaths attributed to malformations of the cardiovascular system. Infants born to Pakistani mothers again featured the greatest excess followed by infants born to African and Indian/Bangladeshi mothers. Infants born to Irish mothers did not show a consistent excess for this group of malformations.

Anomalies of the respiratory system were relatively fewer in number, accounting for only $3 \%$ of deaths from malformations. Infants of mothers of African, Indian/Bangladeshi, and Irish origin showed consistent excess deaths in this group.

\section{OTHER CONGENITAL ANOMALIES}

SMRs for three groups of malformations are shown in table 3 . There were excess deaths for cleft palate, cleft lip, and other anomalies of the upper alimentary tract and the digestive system among infants born to mothers from India/Bangladesh, Pakistan, Africa, and Ireland. The SMRs were highest for those of Indian/Bangladeshi origin.

Anomalies of the genital organs and urinary system were excessive among infants born to Pakistani mothers, followed by those born to Indian/Bangladeshi mothers. Infants born to Irish mothers did not show any excess nor did infants born to African or West Indian mothers.

Limb and other musculoskeletal anomalies accounted for 589 (3\%) deaths overall. Again infants born to Pakistani mothers showed very high SMRs of 502 and 259 for the two periods, the only other group with consistent excess being the infants born to

Table 2 SMRs and numbers for infant deaths and stillbirths, by country of birth of mother, for central nervous system anomalies

\begin{tabular}{|c|c|c|c|c|c|c|c|c|c|c|c|c|}
\hline \multirow{3}{*}{$\begin{array}{l}\text { Mother's country of birth } \\
\text { United Kingdom }\end{array}$} & \multicolumn{4}{|c|}{ Anencephalus } & \multicolumn{4}{|c|}{ Spina bifida } & \multicolumn{4}{|c|}{ Other central nervous system anomalies } \\
\hline & \multicolumn{2}{|c|}{$\begin{array}{l}1975-78 \\
\text { SMR Obs }\end{array}$} & \multicolumn{2}{|c|}{$\begin{array}{l}1979-80 \\
\text { SMR Obs }\end{array}$} & \multicolumn{2}{|c|}{$\begin{array}{l}1975-78 \\
\text { SMR Obs }\end{array}$} & \multicolumn{2}{|c|}{$\begin{array}{l}1979 \_80 \\
\text { SMR Obs }\end{array}$} & \multicolumn{2}{|c|}{$\begin{array}{l}1975-78 \\
\text { SMR Obs }\end{array}$} & \multicolumn{2}{|c|}{$\begin{array}{l}1979-80 \\
\text { SMR Obs }\end{array}$} \\
\hline & 102 & 2700 & 102 & 828 & $105^{*}$ & 2260 & 104 & 917 & 101 & 1165 & 95 & 464 \\
\hline New Commonwealth & 96 & 171 & 100 & 58 & $67^{*}$ & 98 & 87 & 55 & 93 & 74 & 118 & 42 \\
\hline Bangladesh/India & $157^{*}$ & 109 & $185^{*}$ & 42 & 110 & 63 & 105 & 26 & 124 & 39 & 129 & 18 \\
\hline Africa & 97 & 36 & 105 & 15 & 75 & 23 & 116 & 18 & 85 & 14 & 104 & 9 \\
\hline West Indies & $16^{*}$ & 6 & - & - & $26^{*}$ & 8 & $36^{*}$ & 4 & 57 & 10 & 108 & 7 \\
\hline Australia, Canada, and New Zealand & 76 & 8 & 29 & 1 & 58 & 5 & 81 & 3 & 21 & 1 & 47 & 1 \\
\hline Malta, Gibraltar, and Cyprus & $42^{*}$ & 6 & - & - & $17^{*}$ & 2 & 41 & 2 & 110 & 7 & 110 & 3 \\
\hline Remainder of New Commonwealth & 77 & 14 & $16^{*}$ & 1 & $13^{*}$ & 2 & 72 & 5 & 49 & 4 & 129 & 5 \\
\hline Pakistan & $134^{*}$ & 62 & $168^{*}$ & 32 & 110 & 42 & 106 & 22 & $229^{*}$ & 49 & $358^{*}$ & 42 \\
\hline Irish Republic & 116 & 63 & 117 & 15 & 108 & 48 & 121 & 17 & 115 & 29 & 144 & 12 \\
\hline Not stated and/or at sea & $428^{*}$ & 16 & 159 & 1 & $329 *$ & 10 & 293 & 2 & 122 & 2 & $520^{*}$ & 2 \\
\hline
\end{tabular}

$\div$ Observed deaths

* $\mathrm{p}<0.05$ 
Table 3 SMRs and numbers for infant deaths and stillbirths, by country of birth of mother, for circulatory system and respiratory system anomalies

\begin{tabular}{|c|c|c|c|c|c|c|c|c|}
\hline \multirow{3}{*}{$\begin{array}{l}\text { Mother's country of birth } \\
\text { United Kingdom }\end{array}$} & \multicolumn{4}{|c|}{ Circulatory system anomalies } & \multicolumn{4}{|c|}{ Respiratory system anomalies } \\
\hline & \multicolumn{2}{|c|}{$\begin{array}{l}1975-78 \\
\text { SMR Obs }\end{array}$} & \multicolumn{2}{|c|}{$\begin{array}{l}1979-80 \\
\text { SMR Obs }\end{array}$} & \multicolumn{2}{|c|}{$\begin{array}{l}1975-78 \\
\text { SMR Obs }\end{array}$} & \multicolumn{2}{|c|}{$\begin{array}{l}1979-80 \\
\text { SMR Obs }\end{array}$} \\
\hline & 100 & 2692 & 100 & 1277 & 962 & 299 & 98 & 205 \\
\hline New Commonwealth & $126^{*}$ & 234 & 115 & 107 & $168^{*}$ & 35 & 97 & 15 \\
\hline Bangladesh, India & $139^{*}$ & 102 & 132 & 48 & 147 & 12 & 133 & 8 \\
\hline Africa & $158^{*}$ & 62 & 131 & 30 & $343^{*}$ & 15 & 105 & 4 \\
\hline West Indies & 102 & 40 & 78 & 13 & 66 & 3 & 72 & 2 \\
\hline Australia, Canada, and New Zealand & 121 & 14 & 105 & 6 & $457^{*}$ & 6 & 208 & 2 \\
\hline Malta, Gibraltar, and Cyprus & 75 & 11 & 140 & 10 & 60 & 1 & 85 & 1 \\
\hline Remainder of New Commonwealth & 99 & 19 & 58 & 6 & 186 & 4 & - & - \\
\hline Pakistan & $169^{*}$ & 83 & $200^{*}$ & 61 & 74 & 4 & $237^{*}$ & 12 \\
\hline Irish Republic & 109 & 66 & 73 & 16 & 118 & 8 & $239^{*}$ & 9 \\
\hline Not stated and/or at sea & $370^{*}$ & 14 & $404^{*}$ & 4 & 229 & 1 & $607^{*}$ & 1 \\
\hline
\end{tabular}

Observed deaths

- $\mathrm{p}<0.05$

African mothers. Infants born to Indian and Irish mothers did not show a consistent excess.

\section{Discussion}

The study examines stillbirths and infant deaths in England and Wales between the years 1976 and 1980. The analysis is based on the underlying cause of death, as stated by the certifying doctor, and therefore excludes cases where the malformations may have been a contributory factor to death. However, there is no evidence to suggest that there are significant differences in certifying practices for deaths of infants to mothers from different ethnic backgrounds. Malformations not resulting in death are excluded from the study. Clearly the ability of the data on mortality to reflect incidence will depend on the specific condition being studied. The analysis covers stillbirths and all infant deaths to exclude any possible problems of differential reporting of stillbirth and early infant deaths between the $\stackrel{\mathcal{S}}{S}$ different groups investigated in the study. There $\dot{\omega}$ could also be variations among the groups in the pattern of survival of infants with congenita malformations. The proportions dying within the fir ${ }^{\circ} \mathrm{N}$ year could vary.

Though the analysis is based on the information of country of birth of mother, it is considered $\bar{s} c$ reasonable proxy to ethnicity in the childbearing ages. In the analysis we did not attempt to distinguish between Indian and Bangladeshi mothers, who wefe grouped together. The Bangladeshi group, however, is relatively small compared to the Indians in this group.

Excess mortality from all malformations was greatest among infants born to Pakistani mothers

Table 4 SMRs and numbers for other malformations

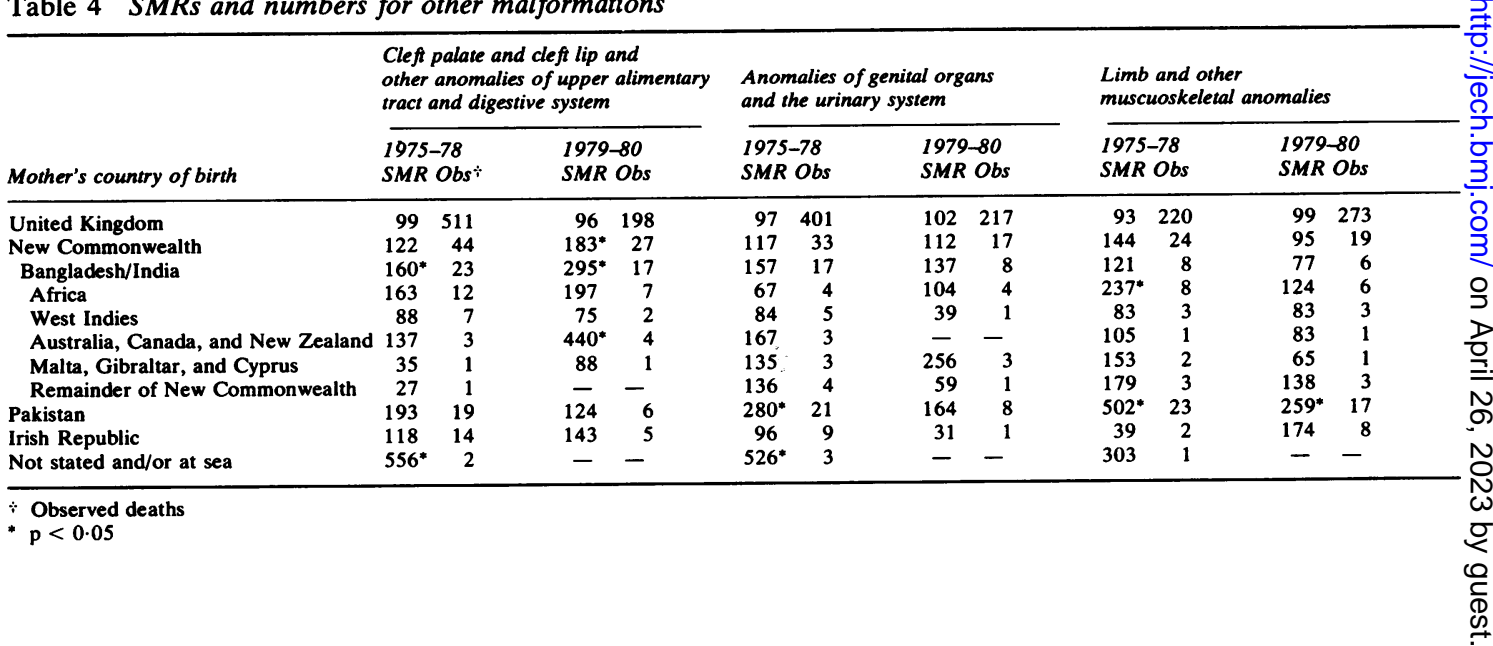


followed by those to Indian/Bangladeshi, African, and Irish mothers. In contrast, infants born to West Indian mothers showed fewer than expected deaths.

Infants born to Pakistani mothers showed excess deaths in all categories of malformations, especially in limb and musculoskeletal anomalies, anomalies of the genital organs and urinary system, other central nervous system anomalies, and cardiovascular anomalies. Infants born to mothers from India and Bangladesh showed overall SMRs of 137 and 136 for the two periods, and they, too, had excess deaths in all categories in the two periods except limb and musculoskeletal defects. The excesses tended to be lower than in infants of mothers from Pakistan except for anencephaly, clefts, and gastrointestinal defects where they appear to be higher.

Leck, ${ }^{4}$ in his study of Birmingham births between 1960 and 1965, showed that Indian and Pakistani mothers as a group did not have a significantly different incidence of congenital malformations, including neural tube defects, oral clefts, and reduction deformities of the limbs. Recent studies from Birmingham have been contradictory. Terry $e t$ $a l$, based on their series of 3996 births in 1979, reported the highest rate for all malformations in Pakistani (29.6/1000) and Bangladeshi (32.6/1000) mothers. Indian mothers had a lower rate $(19 \cdot 5 / 1000)$ than that of the European mothers $(21 \cdot 2 / 1000)$. In a subsequent study ${ }^{6}$ from the same centre, over a three year period which included 1979 , their malformation rates were of a different order of magnitude. The European mothers had a rate of $8 \cdot 5 / 1000$, the highest rate being for Indian mothers $(14 \cdot 2 / 1000)$ followed by Pakistani mothers $(12 \cdot 2 / 1000)$. There are difficulties in the interpretation of their findings as the denominators used are not clearly specified. Also small numbers may have affected the rates in some groups, there being only two congenital malformations in Bangladeshi mothers between 1979 and 1981. In our study there is a clear excess of deaths attributed to malformations among Pakistani and Indian and Bangladeshi groups.

Death rates from malformations overall were raised among infants born to mothers from Africa (SMRs 119 and 123). The malformations that featured most excess among this group were cardiovascular, respiratory, clefts and other gastrointestinal defects, and limb deformities. In contrast to the African mothers, the West Indian mothers showed fewer than expected deaths for practically every malformation. Our findings in the West Indians are in agreement with previously published reports. A low incidence of malformations both in the West Indian population in this country ${ }^{4}$ and in American blacks ${ }^{7}$ has been reported previously. While we found excess malformations in immigrants from Africa, many of these are of Asian origin. It is estimated that just over $60 \%$ of the England and Wales populations in mid-1976 of Commonwealth African origin (excluding Europeans) were of Asian ethnic origin, this population having risen rapidly from less than $50 \%$ in mid-1971. ${ }^{8}$

Infants born to Irish mothers showed overall excess deaths for malformations and especially for those of the central nervous system, respiratory system, cleft lip and palates, and gastrointestinal system. Our findings correspond with the reports of significant excess neural tube defects in those of Irish descent in Birmingham in the 1960s. ${ }^{4}$

Environmental and genetic factors and their interactions, and the uptake of medical care, need to be considered as possible reasons for the variations in mortality among the different ethnic groups. Poor uptake of antenatal facilities and lack of screening may explain some of the differences for certain malformations such as neural tube defects, and chromosomal abnormalities. However this does not correspond with the finding of low mortality in infants of West Indian mothers.

Immigrants from the Indian subcontinent could also possibly suffer as a result of a greater incidence of consanguineous marriages. Terry et al, in their investigation, ${ }^{5}$ showed that in a sample of 314 Pakistani mothers 79\% had married relatives whereas only $26 \%$ of 78 Bangladeshi mothers and $3 \%$ of 486 Indian mothers in their study had done so. There were no marriages to relatives among West Indians and Europeans in their study. This is likely to influence further any genetic susceptibility among those of Asian origin.

Nutritional factors, diseases such as anaemia, osteomalacia, and diabetes, and cultural influences (eg, application of surma) could be contributory to pregnancy outcome in these ethnic groups. On the other hand, mothers from the Indian subcontinent are less likely to consume alcohol or tobacco.

The lower incidence in the West Indians could have a genetic basis as they are more likely to be of mixed descent in contrast to those of African origin. Ascertainment of incidence in the countries of origin, though difficult, will shed further light on the ethnic variation of congenital malformations.

\section{References}

${ }^{1}$ Weatherall JAC. Congenital malformation: Surveillance and reporting. Population Trends 1978, April, London: HMSO. 
${ }^{2}$ Adelstein AM, MacDonald Davies IM, Weatherall JAC. Perinatal and infant mortality; social and biolgical factors 1975-77. Studies on Medical and Population Subjects No. 41. London: Office of Population Censuses \& Surveys, 1980.

${ }^{3}$ World Health Organization. International classification of diseases 1975 Revision, Geneva: WHO, 1978.

${ }^{4}$ Leck I. Ethnic differences in the incidence of malformations following migration. Br J Prev Soc Med 1969; 23: 166.
${ }^{5}$ Terry PB, Condie RG, Settatree RS. Analysis of ethnic differences in perinatal statistics. $\mathrm{Br}$ Med J 1980; 281: 1307.

${ }^{6}$ Terry PB, Condie RG, Mathew PM, Bissenden JG. Ethnic differences in the distribution of congenital malformations. Postgrad Med J 1983; 59: 657.

${ }^{7}$ Erickson JD. Racial variations in the incidence of congenital malformations. Ann Hum Genet Lond 1976; 39: 315.

${ }^{8}$ OPCS New Commonwealth and Pakistani population estimates. Population Trends 1977; 9: London: HMSO. 